\title{
Distribution Network Condition Based Maintenance Application Present Situation and Development
}

\author{
Su Yanfei, Zhao Changqing, Zhao chenxu, Xu Long, and Xu Heng
}

\begin{abstract}
From a background of domestic electric power enterprise distribution network state maintenance, State maintenance for the distribution network development status quo and the situation at home and abroad, Overhaul technology and management experience combined with state of the distribution network, Explore with grid equipment condition based maintenance technology application and development in the future.
\end{abstract}

Index Terms-Distribution network, maintenance, present situation, development.

\section{Present Situation of Distribution Network MAINTENANCE}

Currently, most of the power supply enterprise distribution network maintenance and distribution network management model using "periodic maintenance. This way is relatively simple, and the staff is just by virtue of the experience to judge the condition of the equipment, the efficiency is low, and achieving the desired effects. Periodic maintenance is carried out in accordance with the climate goes, generally concentrated in the spring and autumn. Longer periodic maintenance of power lines, equipment safety hazards cannot be timely detection, and cannot guarantee the operation of the monitoring of the distribution lines and equipment. Take periodic maintenance, only take into account the "face" and cannot take into account every point, only take into account a period of time rather than all the time. Ensure periodic maintenance of the application, technical staff only individually detected using a handheld device, this method can only be important, hidden spots may occur in the processing, not a potential danger point for effective monitoring and treatment. Found in the periodic maintenance problem, not by virtue of the increase in personnel can be solved. In order to ensure the safe and reliable $10 \mathrm{kV}$ distribution network run, it is necessary to introduce a new concept, the use of new technologies, the purchase of new equipment, the application of the new model in order to really solve the above problems.

\section{THE NECESSITY FOR IMPLEMENTATION OF THE DisTRIBUTION OF CONDITION-BASED MAINTENANCE}

Distribution network maintenance definition: distribution network condition-based maintenance is based on safety,

Manuscript received April 20, 2013; revised June 14, 2013.

The authors are with the Bayannur Electric Power Bureau of Inner Mongolia Electric Power Group Co., Ltd. (e-mail: bmzcx99@ sina.com, zhaochangqing339@126.com, bmxx117611@sina.com, nmbmxuheng@163.com). reliability, environmental, and cost-based, advanced technical means and detection equipment distribution network equipment status evaluation, risk assessment, maintenance decision and ultimately achieves the safe and reliable operation of equipment operation, and a new maintenance strategy to ensure uninterrupted power supply. Distribution network condition-based maintenance is based on the $10 \mathrm{kV}$ line, real-time status of equipment management, not monthly, annual and seasonal cycle of inspections are carried out without any constraints and limiting visits the place, time and number of inspections, can be an effective means of science and technology at any time monitoring and management, it is a cycle of inspections of distribution network effective supplement to make up for the lack of periodic visits, reduce the labor intensity of the patrol officers. Promotion and application of condition-based maintenance of the distribution network, not only on the distribution network line, equipment inspections, and to solve the contradiction of long lines, fewer personnel, more effective management of the distribution network, and more economical [1].

The necessity to maintenance the implementation of distribution network is mainly reflected in the following aspects:

1) The defects of the running line, the device can be effectively found

Distribution network lines and more concentrated in the city, the lines walking trails more complex. The past periodic scheduled maintenance area distribution network line equipment maintenance on a regular basis. Because of the difficulties of the power line outage distribution lines, equipment preventive maintenance time is short, overhaul more. For example, the overhead lines at least three years, kicking poles check once the distribution transformer general cleaning maintenance once annually must preventive tests, various types of circuit breakers and switches 1-3 years preventive tests must be carried out. In accordance with the maintenance mode, some hidden safety danger point is not always to discover, nor timely processing. It must be required from time to time, at any time lines, equipment monitoring and monitoring and control, to the point of failure and the hidden points in the bud.

2) distribution network running maintenance costs savings Regular maintenance and regardless of the status of the device maturity compulsory, with grid lines, equipment management science and rationality, practical guidance, may lack or excess raw occurred to property resulting waste. If the implementation of the state maintenance of distribution networks, it can effectively solve such problems. 
3) Improve the reliability of power supply and growth for the expansion of sales

Plans to periodically run annual maintenance, not only to spend a lot of manpower and material resources of the electricity sector, but more importantly, affect the reliability of the electricity outage maintenance, but also affect people's normal life and production. The planned outage caused by regular maintenance and inspections, the impact to the city power supply reliability and power supply. With the development of the situation, the whole society is increasing the reliability requirements of the power supply, a large number of regular maintenance necessary arrangements become increasingly difficult time. With the increasingly high user of electricity service requirements, the power supply safety and reliability will be put forward higher requirements. Regularly patrol the long-term impact and challenges.

\section{Distribution Network CONDITION BASED MainTENANCE TEChNOLOGY APPLiCATION Situation}

Mentioned earlier state maintenance work abroad, mainly large grid equipment online monitoring, and for the distribution network less. Maintenance work of the domestic distribution network as the main ways to plan periodic maintenance, distribution network state maintenance is assisted maintenance mode, with emphasis on the distribution lines, distribution transformer, column switch status detection data collection and analysis. Relatively mature detection technology based on the full use of the existing technical conditions and equipment resources, the conventional online monitoring and data analysis, and improve the status of distribution line diagnosis, evaluation of the level of maturity compulsory gradually change the traditional maintenance mode, to achieve a combination of modes of distribution network state maintenance and planned maintenance.

\section{A. The Situation Abroad}

In 1978, the Electric Power Research Institute (EPRI), the research and application on the state of the electrical equipment maintenance. The United States DuPont is the first to propose a condition-based maintenance (CBM, Condition Based Maintenance), also known as predictive maintenance (PDM Predictive Diagnostic Maintenance).This maintenance the current working conditions of the equipment, through state monitoring tools, diagnostic equipment, health level, in order to determine the best time of the equipment you need to repair or maintenance. It is a state-of-the-art maintenance and condition-based maintenance, reduce downtime, improve equipment reliability and availability factor, extend equipment life, reduce repair and maintenance costs, and improve equipment performance, and improve economic efficiency. Japanese power equipment since the eighties, the maintenance of the state based on state analysis, and online testing. In most European countries is also ongoing reform of the maintenance system, the direction is condition-based maintenance [2].

\section{B. The Domestic Situation}

In 2010, the State Grid Corporation of start of the first five Distribution Networks maintenance pilot units, Xingtai, Hebei, Shandong, Qingdao, Zhejiang Jinhua, Wuxi, Jiangsu, Hubei Jingzhou.Jinhua Electric Power Bureau in 2011 and took the lead through acceptance, to become the country's first on-line operation. The state maintenance implementation of the distribution network in the State Grid Corporation to carry out a comprehensive, and achieved certain results.

\section{1) Column switch running state detection}

The column switch operating status of condition-based maintenance of the distribution network blind spots and difficult, Jinhua Electric Power Bureau column test and live working technology organic combination of the first in the country to live detection column switch, fill with grid equipment state detection technologies blank.

\section{2) Overhead lines Infrared Temperature imaging}

The early simple point thermometers upgrade infrared imager, the infrared imager put into use since 2010 through a number of major or urgent defects easier to discover and deal with [3].

\section{3) The switching station device electrically charged detection}

Online temperature measurement using advanced technology switch cabinet, SF6 switching station indoor installation SF6 gas leakage monitoring alarm system, indoor environment, automatic control and other advanced equipment to monitor management, and achieved good results.

\section{Distribution Network CONDITION TECHNOLOGY DEVELOPMENT}

\section{A. Distribution Networks Maintenance Application of the Main Technical}

\section{1) Wireless sensor network technology}

The wireless sensor networks (Wireless Sensor Network, WSN) is the power supply, provided by a battery or vibration generator constituting the wireless sensor network node, by the random distribution of integration sensor, data processing unit and a communication module micro node through wireless communication and form a the self-organizing network system. It can acquire the device's digital signal is transmitted through a wireless sensor network wireless gateway to the monitoring center, directly into the computer, for analysis and processing, remote data acquisition and condition monitoring. This technique is mainly used for distribution transformer winding temperature, surge arresters, on-line monitoring of the column switch [4].

\section{2) Infrared thermometry technology}

Infrared temperature measurement technology is a part of the temperature measurement and distribution equipment to determine the thermal fault, its technical superiority is practical, telemetry within a certain distance can be measured directly, and displays the temperature gradient image, determine fault occurred. 


\section{3) Partial Discharge Monitoring Technology}

The partial discharge detection is based on the generated electrical, optical, and other phenomena in the event of a partial discharge as the basis to determine the status of the partial discharge. Partial discharge detection technology includes a variety of detection methods of pulse current method, UHF detection method, and transient-to-ground voltage detection method.[5]

\section{B. Development of Distribution Networks maintenance}

The Distribution Networks maintenance the dynamic management of the operation of the power distribution system maintenance, a complete real-time, on-line monitoring system should be the establishment of a full range of multi-system components. According to their works classification shall establish the following three systems:

\section{1) Site running environmental monitoring system}

Micro-meteorological monitoring system: Use of wireless sensor technology, through effective monitoring of wind speed, wind direction, rainfall, ambient temperature, temperature and other weather conditions, early analysis to judge the operation of various types of equipment, the development of effective measures;

Insulator Contamination Degree monitoring system: Fiber density sensor to monitor the extent of the insulators air filthy, through the establishment of a mathematical model, the calculated salt density filthy warning, mapping guide cleaning and polluted area to provide basic information;

Infrared line fault monitoring system: The use of high-quality infrared temperature measurement devices and imagers, receiving or shooting from distribution equipment surface infrared can detect the temperature of the specific parts of the transformer, column switch and indoor switch cabinet, transformer according to the temperature signal and the change analysis column on the type of switch and indoor switch cabinet failure. Temperature distribution to turn into a video signal, the signal can be fed to the monitoring point through the high frequency amplifier circuit, for the determination of the type of distribution equipment failure, temperature, power, and whether the discharge of the point of failure and failure trends, the fault point provide the basis for accurate positioning.

\section{2) Electrical operation Condition monitoring system}

The distribution transformer winding temperature monitoring system: through real-time monitoring of transformer state, combined with the basic parameters of the transformer, the real-time environment temperature parameters, the transformer winding temperature is calculated through the transformer temperature rise thermal circuit model analysis, application analysis system based on transformer temperature rise limit prediction model mathematical model to determine the winding temperature of the transformer current and temperature rise threshold value, direct measurement data to the transformer health status provided. And through the temperature rise limit the application of the prediction model, using the method of winding temperature real-time tracking mode ", the real-time monitoring of the distribution transformer temperature more operational and security.
The grounding resistance of wireless detection system: Using wireless sensors to give measured grounding circuit to an excitation signal, and an electric potential $\mathrm{E}$ is induced in the loop to be measured in the circuit under test to generate a current I, in the role of a potential E. Sensor measurements of $\mathrm{E}$ and $\mathrm{I}$, and by the formula: $\mathrm{R}=\mathrm{E} / \mathrm{I}$ can be obtained by measured loop resistance;

$10 \mathrm{KV}$ AC metal oxide surge arresters wireless monitoring system: Sensors installed in the operation of the device, using the GPRS wireless network, the line arrester of the working current, leakage current and other popular data acquisition, remote transmission to the receiving terminal;

The ground fault diagnosis of column switches online monitoring system: Wireless sensor technology for online monitoring of the switch device itself mechanical performance the closing coil current changes in the vibration signal, the insulation condition. Monitoring circuit load current information at the same time can be achieved, single-phase ground fault, phase fault monitoring.

\section{3) The mechanics state monitoring system}

The type of distribution line conductors is more, according to its operational features to its sag of the wire, the distance and wire connection, contact wear discharge inspections and monitoring.

Distribution line towers including steel rod, tube tower, concrete pole, tower material of rust, corrosion, loose bolts, tower displacement, tilt inspections and monitoring.

Fittings including standard and non-standard fittings with their body and bolt rust, corrosion, loose bolts, tilt the inspections and monitoring.

The foundation of the foundation include tower based on various types of power distribution equipment and cable trench wells. According to the climatic conditions, corrosion, water, ground, shift inspections and monitoring.

\section{CONCLUSION}

Distribution network state maintenance is the inevitable trend of development of smart grid, distribution network maintenance and related technologies for the smart grid provides a detailed theoretical basis and technical support for the grand blueprint. Condition-based maintenance management of the distribution network in China technology research is still in its infancy, from various regions of China in the next few years, we actively explore, pay close attention to the research and development of new technologies to promote the state of the distribution network maintenance standardized intelligent, meticulous forward.

\section{REFERENCES}

[1] W. H. Long, "Practice effective distribution network equipment Condition based maintenance," Theoretical study of city construction, vol. 1, no. 9, pp. 18-19, 2012.

[2] F. X. Li, "Distribution network online condition-based maintenance techniques of exploration," New technology and new products, vol. 1, no. 3, pp. 10-11, 2012.

[3] C. M. Ji and Y. Chen, "Condition-based maintenance management of distribution network equipment," Hubei Electric Power, vol. 4, no. 5, pp. 6-7, 2005.

[4] S. L. Weng and Z. Y. Wang, "Implementation of the strategy research carried out with the grid line condition-based maintenance," Journal of Huzhou Teachers College, vol. 3, no. 6, pp. 12-14, 2009. 
[5] C. Y. Gao, "Domestic and foreign electrical equipment condition based maintenance and development overview," Heilongjiang Science and Technology Information, vol. 3, no. 10, pp. 20, 2012.

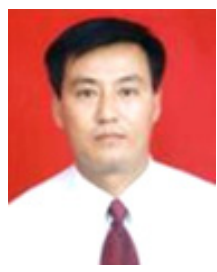

Su Yanfei was born in 1968, senior engineer, graduated from North China Electric Power University, Engineering Master.

He went to study in the U.S. in 2005. Based on the actual conduct of management and technological innovation, scientific and technological achievements of the national grid company and Technology Progress Award. Incumbent Inner engineering and technical experts. Main research direction is distribution network automation, scheduling management, smart grid.

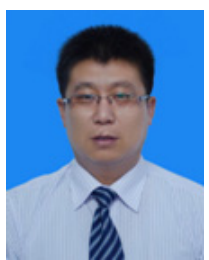

Zhao Chanqing was born in 1974, senior engineer, graduated from North China Electric Power University, Engineering Master.

$\mathrm{He}$ has been working in the distribution network planning, power grid construction, smart grid, over the years has participated in domestic and international power conference and published more than 20 papers, scientific and technological achievements won several innovation awards. Research direction is distribution network automation, scheduling management, smart grid.

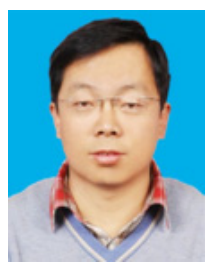

Zhao Chenxu was born in 1975, senior engineer, graduated from North China Electric Power University, Engineering Master.

He has been working in the distribution network planning, power grid construction, smart grid, over the years has participated in domestic and international power conference and published more than 20 papers, scientific and technological achievements won several innovation awards. Research direction is distribution network automation, scheduling management, smart grid.

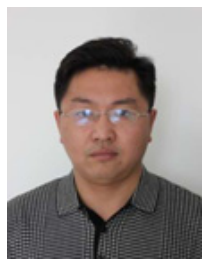

Xu Long was born in 1975, senior engineer, graduated from North China Electric Power University, Engineering Master.

He has been working in the distribution network planning, power grid construction, smart grid, over the years has participated in domestic and international power conference and published more than 20 papers, scientific and technological achievements won several innovation awards. Research direction is distribution network automation, scheduling management, smart grid.

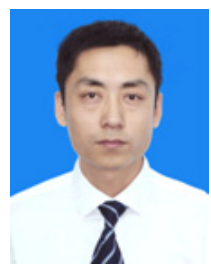

Xu Heng was born in 1978, senior engineer, graduated from North China Electric Power University, Engineering Master.

He has been working in the distribution network planning, power grid construction, smart grid, over the years has participated in domestic and international power conference and published more than 10 papers, scientific and technological achievements won several innovation awards. Research direction is distribution network automation, scheduling management, smart grid. 